\title{
Stage-related differences in rat seminiferous tubule contractility in vitro and their response to oxytocin
}

\author{
G C Harris and H D Nicholson
}

Department of Anatomy, University of Bristol, School of Medical Sciences, Bristol BS8 1TD, UK

(Requests for offprints should be addressed to G C Harris)

\begin{abstract}
Oxytocin (OT) is present in the mammalian testis and has been shown to play a role in the modulation of seminiferous tubule contractility and steroidogenesis. However, stage-specific effects of the peptide have not been previously investigated. In this study, computer-assisted analysis and time-lapse videomicrography were used to investigate basal contractility and the response to OT of seminiferous tubules at specific stages of the spermatogenic cycle. Adult rat testes were placed in fresh oxygenated DMEM F12 medium, decapsulated, and the tubules gently teased apart. Stages were identified by transillumination and a $10 \mathrm{~mm}$ section of tubule at each of stages IV-V, VII-VIII and XIII-I was placed in a microslide chamber and perifused with medium. After a control period of $3 \mathrm{~h}$, OT ( $2 \mathrm{nM}$ ) was given for $1 \mathrm{~h}$, followed by another control period of $1 \mathrm{~h}$. The experiment was repeated using tubules
\end{abstract}

from different rats and data were analysed to give arbitrary units of tubule contractility. Contractility was observed in all the tubules studied and the contractile activity was shown to vary depending on the stage of the spermatogenic cycle. Mean basal contractility at stages VII-VIII, the time when sperm are shed from the epithelium, was significantly lower than that at stages IV-V and XIII-I. The response of the tubules to OT was also stagedependent, with the peptide producing the largest increases in contractile activity at stages VII-VIII and having no effect at stages IV-V. We postulate that these stagespecific differences in basal and OT-stimulated contractility may be important in co-ordinating the movement of developing germ cells towards the lumen of the seminiferous epithelium and in the process of spermiation. Journal of Endocrinology (1998) 157, 251-257

\section{Introduction}

Spermatogenesis is an organised process, which in the rat occurs in an ordered fashion, producing 14 distinct histological stages arranged linearly along the seminiferous tubule (Leblond \& Clermont 1952). During their development, the germ cells not only complete a series of mitotic and meiotic divisions, but also have to move from the base of the tubule to the lumenal surface and undergo major morphological changes. Non-motile spermatozoa are shed from the seminiferous epithelium at the end of stage VIII and are transported through the tubular lumen to the rete testis. A number of mechanisms have been hypothesised to be involved in the shedding of sperm from the seminiferous epithelium (spermiation). These include the formation of tubulobulbar complexes (Gravis 1980), the breakdown of junctional specialisations between the germ cells and the supporting Sertoli cells (Romrell \& Ross 1979) and the involvement of proteases at stages VII-VIII of the cycle (Lacroix et al. 1981, Vihko et al. 1984, Erickson-Lawrence et al. 1991).

The movement of spermatozoa from the testis to the epididymis, where they become motile, has been postulated to occur by a combination of secretion and flow of fluid from the seminiferous tubules and contractile activity of the tubules themselves. Each tubule is surrounded by a layer of smooth muscle-like cells, myoid cells, which produce contractile movements of the tubule (Roosen-Runge 1951). More recently these movements have been characterised and two types of contractile activity have been demonstrated (Worley et al. 1984), type A comprising continual, 'vibratory' movements involving small segments of the tubule wall, and type B which are intermittent contractions of large segments of the tubule. These latter contractions are accompanied by movement of the lumenal contents and are thought to be involved in transporting spermatozoa from the testis. The function of the type A movements is unknown, although these movements may assist in the translocation and subsequent shedding of germ cells from the seminiferous epithelium. Such studies were performed in vitro and it is possible that contractility of tightly packed seminiferous tubules in vivo may not be as great. The testis of the rat is not very fibrous when compared with that of the ram, where the testis consists of a very fibrous interstitium, yet, in the ram, movements of the 
seminiferous tubules contained within whole pieces of excised testis can be observed in vitro (G C Harris, unpublished observations). Furthermore, in the rat, contractions have been observed in gently teased out seminiferous tubules in vivo (H D Nicholson, unpublished observations), indicating that the movement observed in such studies in vitro is not merely an artefact caused by excision and isolation of the seminiferous tubule in a perifusion chamber.

A variety of substances have been shown to affect myoid cell activity, including oxytocin (OT) (Worley et al. 1984), vasopressin (Pickering et al. 1989), prostaglandins (Buhrley \& Ellis 1975) and endothelin (Filippini et al. 1993, Tripiciano et al. 1996). OT is produced by Leydig cells (Nicholson \& Hardy 1992) and increases the contractility of seminiferous tubules in vitro (Niemi \& Kormano 1965) in a dose-dependent manner (Worley et al. 1988) at concentrations similar to those found in the testis (Pickering et al. 1989). Selective Leydig cell depletion with the drug ethane dimethane sulphonate reduces testicular OT and decreases seminiferous tubule contractility in vitro, but contractility can be restored by treatment with OT (Nicholson et al. 1987). In addition, treatment of hypogonadal mice with luteinising hormone or testosterone results in the appearance of both testicular OT and tubular contractility (Nicholson et al. 1986). This, and the evidence that testicular OT is regulated by the seminiferous epithelium (Nicholson et al. 1994), suggests a physiological role for OT in the regulation of tubule contractility. Additionally, although vasopressin has been shown to be at least ten times more potent in stimulating rat seminiferous tubule contractility in vitro than OT (Harris \& Nicholson 1998), it was shown in the same study, by the use of specific OT and vasopressin antagonists, that vasopressin acts via $\mathrm{V}_{1 \text { a }}$ receptors to stimulate contractile activity, whilst OT may act via a receptor which differs from the classical $\mathrm{V}_{1 \mathrm{a}}$ and uterinetype OT receptor. This may also explain the current inability to localise OT receptors on the seminiferous epithelium.

In the epididymis and ductus deferens it has been postulated that OT-induced contractile activity is important in sperm transport (Voglmayr 1975), but more recent evidence suggests that OT may play another role in the testis. Preliminary studies in vivo have shown that OT may also affect spermiation, since administration of the peptide advanced, and treatment with an OT antagonist delayed, the onset of spermiation in the pubertal rat (Frayne et al. 1996). If tubule contractility and testicular peptides, such as OT, are involved in the movement and shedding of germ cells, then one would expect these parameters to change during the spermatogenic cycle. We have used computer-assisted analysis and time-lapse videomicrography to investigate basal contractility and the response to OT of seminiferous tubules at specific stages of the spermatogenic cycle.

\section{Materials and Methods}

\section{Preparation of seminiferous tubules}

Adult male Sprague-Dawley rats were killed by cervical dislocation. Testes were removed and decapsulated. The seminiferous tubules were submerged in pre-oxygenated Dulbecco's modified Eagle's medium (DMEM F12; Gibco Ltd, Paisley, Strathclyde, UK) supplemented with penicillin and streptomycin $\left(50 \mathrm{U} \mathrm{ml}^{-1}\right.$ and $50 \mathrm{mg} \mathrm{ml}^{-1}$ respectively, Sigma Chemical Co., Poole, Dorset, UK) at $34^{\circ} \mathrm{C}$, and gently teased apart. Stages of the spermatogenic cycle were identified by transillumination as described by Parvinen \& Ruokonen (1982), and approximately $10 \mathrm{~mm}$ of tubule at each of stages IV-V, VII-VIII and XIII-I was excised and drawn into a microslide chamber and then perifused with fresh DMEM F12 medium (with antibiotics) at $1.25 \mathrm{ml} \mathrm{h}^{-1}$ using a peristaltic pump.

\section{The perifusion chamber}

A microslide (Camlab Ltd, Cambridge, Cambs, UK) with an inner path length of $400 \mu \mathrm{m}$ was used for containment of the seminiferous tubule and was connected to silicone tubing (Anachem, Luton, Beds, UK). The entire apparatus was enclosed in a cabinet held at the temperature of $34{ }^{\circ} \mathrm{C}$ and suspended on an anti-vibration table (U-frame Isolator, Ealing Electro-optics, Ealing, UK).

\section{Peptides}

All peptides used in this study were first dissolved in distilled water and then diluted in culture medium to the appropriate concentration. OT (Cambridge Research Biochemicals, Cambridge, Cambs, UK) was given at a concentration of $2 \mathrm{nM}$ in the perifusion chamber. The OT antagonist desGly- $\mathrm{NH}_{2}, \mathrm{~d}\left(\mathrm{CH}_{2}\right)_{5}\left[\mathrm{D}-\mathrm{Tyr}^{2}, \mathrm{Thr}^{4}\right] \mathrm{OVT}$ and the vasopressin antagonist Phaa-D-Tyr(Me)-Phe-GlnAsn-Arg-Pro-Arg-Tyr- $\mathrm{NH}_{2}$ used in this study were kindly donated to us by Dr M Manning (Medical College of Ohio, Toledo, $\mathrm{OH}, \mathrm{USA}$ ) and were used at doses similar to their in vitro $\mathrm{pA}_{2}$ values in rat uterus and liver respectively (Schmidt et al. 1991, Manning et al. 1995).

\section{Stage-dependent changes in basal and OT-stimulated contractility}

Segments of tubules were prepared as above and perifused for $3 \mathrm{~h}$ in control medium before perifusion with medium containing OT $(2 \mathrm{nM})$ for $1 \mathrm{~h}$. This was followed by perifusion for a further hour with control medium. The experiment was repeated using tubules from different animals. Stage VII-VIII tubules were also treated with $8 \mathrm{nM}$ and $20 \mathrm{nM} \mathrm{OT}$. 
The effect of OT and vasopressin antagonists on basal tubule contractility

To investigate whether basal contractility might be due to the effects of endogenous neurohypophysial peptides, tubules were prepared as above and after a $3 \mathrm{~h}$ control period perifused with the OT antagonist, desGly-NH ${ }_{2}, \mathrm{~d}\left(\mathrm{CH}_{2}\right)_{5}\left[\mathrm{D}-\mathrm{Tyr}^{2}\right.$, Thr $\left.{ }^{4}\right] \mathrm{OVT}(2 \mu \mathrm{M})$ and the vasopressin antagonist Phaa-D-Tyr(Me)-Phe-Gln-AsnArg-Pro-Arg-Tyr- $\mathrm{NH}_{2}(20 \mathrm{nM})$ for $1 \mathrm{~h}$.

\section{Basal contractility and spermiation}

In order to investigate whether shedding of sperm was related to changes in contractility, basal contractility was examined at stage IX, i.e. after shedding of sperm, and then from the adjacent stage VIII of the same tubule. Measurement of basal contractility at stage IX was performed for approximately $40 \mathrm{~min}$, followed by a further 40 min measurement at the adjacent stage VIII of the same tubule. Recordings were taken $50 \mu \mathrm{m}$ either side of the stage VIII/stage IX boundary, which was easily distinguished by the abrupt change from dark to light lumen associated with spermiation.

\section{Contractility measurement}

Seminiferous tubule contractility was monitored as previously described by Worley \& Leendertz (1988). Briefly, $\times 12$ time-lapse videomicrographic recordings were performed on tubules in vitro. Movement was quantified using an electronic bar, superimposed on a vertically positioned tubule, which measured the changes in contrast which occurred on a video screen when the tubule moved laterally. These changes in contrast were converted to voltages and recorded by a computer. The amplitude and duration of contractions were analysed to give arbitrary units (a.u.) of contractile activity, such that 10 a.u. represented a $10-$ fold increase in activity compared with 1 a.u. This method was very sensitive, with movements of $<0.5 \mu \mathrm{m}$ being detectable by the equipment. Mean contractility was calculated over 5 min intervals unless otherwise stated. Linear interpolation of basal contractility, as described in Harris \& Nicholson (1998), was used to measure the response to OT to take into account any shifting baseline of tubule contractility. The diameter of each seminiferous tubule was also measured to investigate whether the size of the tubule was related to its contractile activity.

\section{Data analysis}

Data were expressed as means \pm S.E.M. In all experiments, data were normally distributed and possessed similar variance. Responses to peptides were expressed as both the ratio and difference between the actual contractility

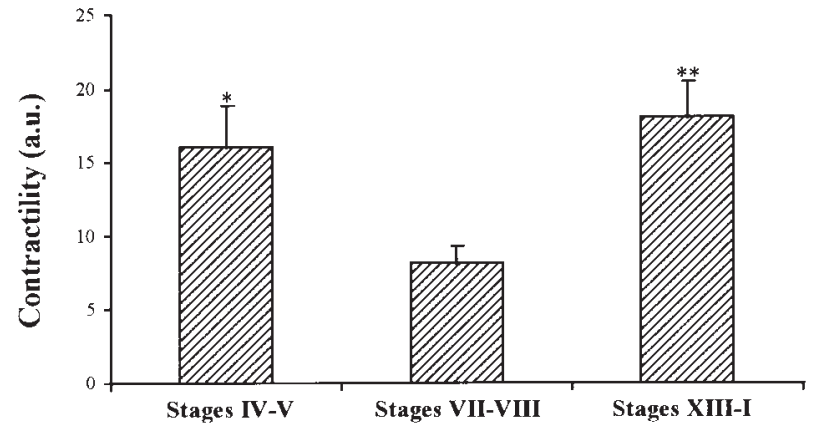

Figure 1 Mean basal contractility of seminiferous tubules at different stages of the spermatogenic cycle. Stages IV-V and XIII-I, $n=6$; stages VII-VIII, $n=15$. ${ }^{*} P<0 \cdot 05,{ }^{*} P<0 \cdot 01$ vs stages VII-VIII.

during treatment' (a.u.) compared with the 'linearly interpolated contractility during treatment' (a.u.). Data were expressed in both ways to allow for variations in basal contractility that occurred between tubules at different stages of the spermatogenic cycle (ANOVA, $P<0 \cdot 05$ ). Student's paired $t$-tests were performed to test for significant OT-induced increases in contractility. Student's $t$-tests and ANOVA were used to compare basal contractility with the response to OT at different stages of the spermatogenic cycle. Values were considered to be significantly different if $P<0 \cdot 05$.

\section{Results}

\section{Basal contractility of seminiferous tubules}

Basal contractile activity was observed in all of the tubules examined. Contractility varied significantly (ANOVA, $P=0 \cdot 001$ ) between tubules at different stages of the spermatogenic cycle (Fig. 1), with basal contractile activity being significantly lower at stages VII-VIII compared with stages IV-V $(P<0 \cdot 05)$ and XIII-I $(P<0 \cdot 01)$, and highest at stages XIII-I.

Perifusion with the OT antagonist desGly$\mathrm{NH}_{2}, \mathrm{~d}\left(\mathrm{CH}_{2}\right)_{5}\left[\mathrm{D}-\mathrm{Tyr}^{2}, \mathrm{Thr}^{4}\right] \mathrm{OVT} \quad(2 \mu \mathrm{M})$ and the vasopressin antagonist Phaa-D-Tyr(Me)-Phe-Gln-AsnArg-Pro-Arg-Tyr- $\mathrm{NH}_{2}(20 \mathrm{nM})$ did not affect basal contractility (Fig. 2) at stages IV-V and XIII-I. Separate incubation with each of these antagonists has also been shown to specifically block OT- and vasopressin-induced increases in contractility at stages VII-VIII, whilst again having no effect on basal contractility (Harris \& Nicholson 1998).

Basal contractile activity was found to alter around the time of spermiation. Tubules exhibited greater basal contractile activity at stage IX, immediately after sperm had been shed, than at stage VIII for the same tubule (Fig. 3). The site of spermiation did not change during any of the experiments. 
a

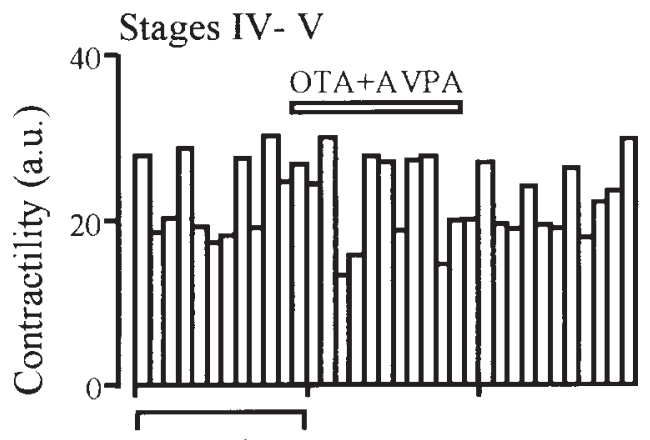

b

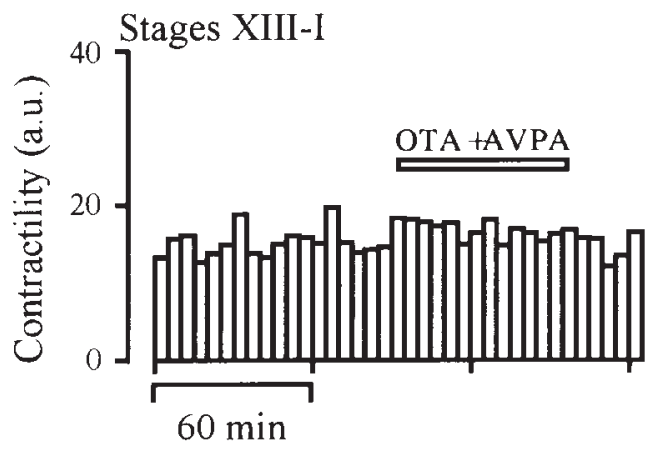

Figure 2 Representative contractility recordings showing the lack of effect of OT (OTA, $2 \mu \mathrm{M}$ ) and vasopressin (AVPA, $20 \mathrm{nM}$ ) antagonists on seminiferous tubule contractility at (a) stages IV-V and (b) stages XIII-I of the spermatogenic cycle. Each bar represents the mean contractility of the tubule over a $5 \mathrm{~min}$ period.

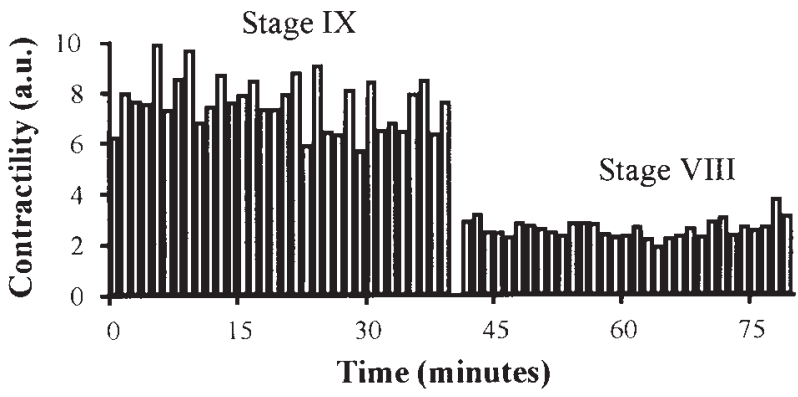

Figure 3 Representative trace of seminiferous tubule contractility at stage IX and stage VIII of the spermatogenic cycle within an individual tubule. Each bar represents the mean contractility of the tubule over a $1 \cdot 25$ min period.

The diameter of the seminiferous tubules also varied with the stage of the spermatogenic cycle (Fig. 4). The tubular diameters were significantly larger at stages VIIVIII compared with stages IV-V and XIII-I (ANOVA, $P<0 \cdot 001)$. In Fig. 5, the basal contractility is plotted against tubule diameter. No significant correlation was seen between contractile activity and tubule diameter when all the tubules were considered. However, tubules at stages XIII-I showed a significant positive correlation $(P<0 \cdot 05)$ of tubule diameter with basal contractility.

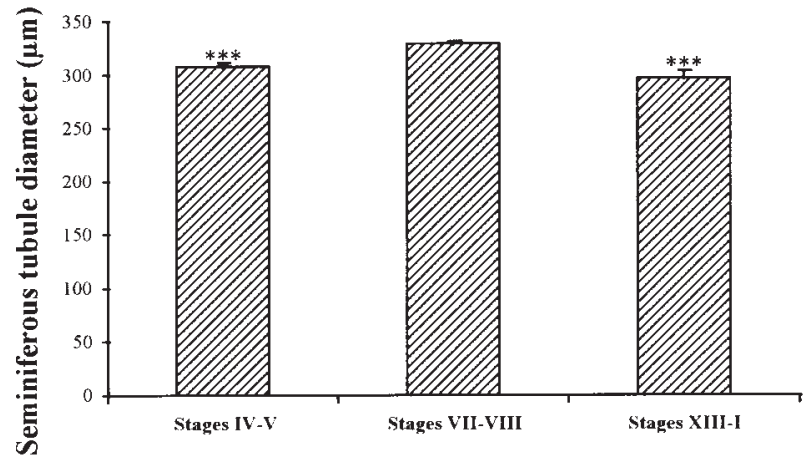

Figure 4 Seminiferous tubule diameter at stages IV-V $(n=8)$, VII-VIII ( $n=91)$ and XIII-I $(n=9)$ of the spermatogenic cycle. Data are expressed as means \pm S.E.M. ${ }^{* *} P<0 \cdot 001$ vs stages VII-VIII.

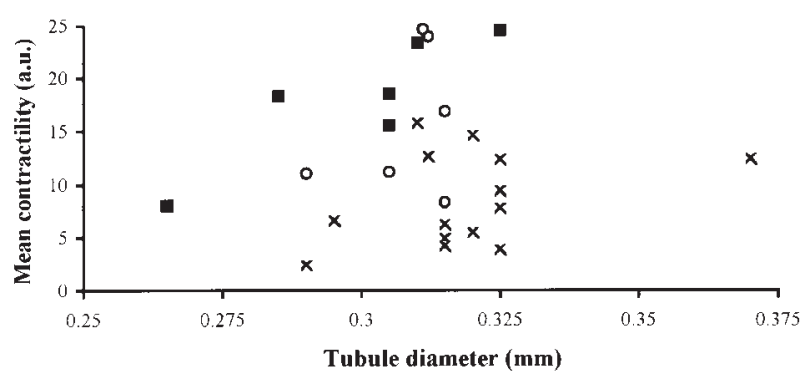

Figure 5 Scatter diagram of tubule diameter vs basal contractility. $O$, stages IV-V $(n=6) ; \times$, stages VII-VIII $(n=15) ; \mathbf{\square}$, stages XIII-I $(n=6)$.

\section{Effects of OT on seminiferous tubule contractility}

OT (2 nM) significantly increased tubule contractility at stages VII-VIII $(P<0 \cdot 001)$ and XIII-I $(P<0 \cdot 05)$ compared with the control period (Fig. 6). The increase in contractility was larger at stages VII-VIII (33\%) than at stages XIII-I (7\%). These effects were seen when the results were expressed as the increase in contractility (Fig. 6a), and as the relative contractile response (Fig. 6b) compared with the activity during the control period. Furthermore, OT increased seminiferous tubule contractility in a dosedependent manner at stages VII-VIII (Fig. 7). Stages IV-V did not show a significant response to OT $(2 \mathrm{nM})$. The relative contractile response to OT $(2 \mathrm{nM})$ at stages VII-VIII was significantly higher $(P<0 \cdot 05)$ than that at stages XIII-I (Student's unpaired $t$-test).

To investigate whether the response to OT was determined by the initial contractile activity of the tubule, the basal contractility of seminiferous tubules was plotted against the relative contractile response (Fig. 8a) and OT-induced increase in contractility (Fig. 8b). There was no significant correlation between basal contractility and OT-induced contractile responses at any of the stages of the spermatogenic cycle examined, regardless of whether the data were expressed as the increase in contractility or the relative contractile response. 


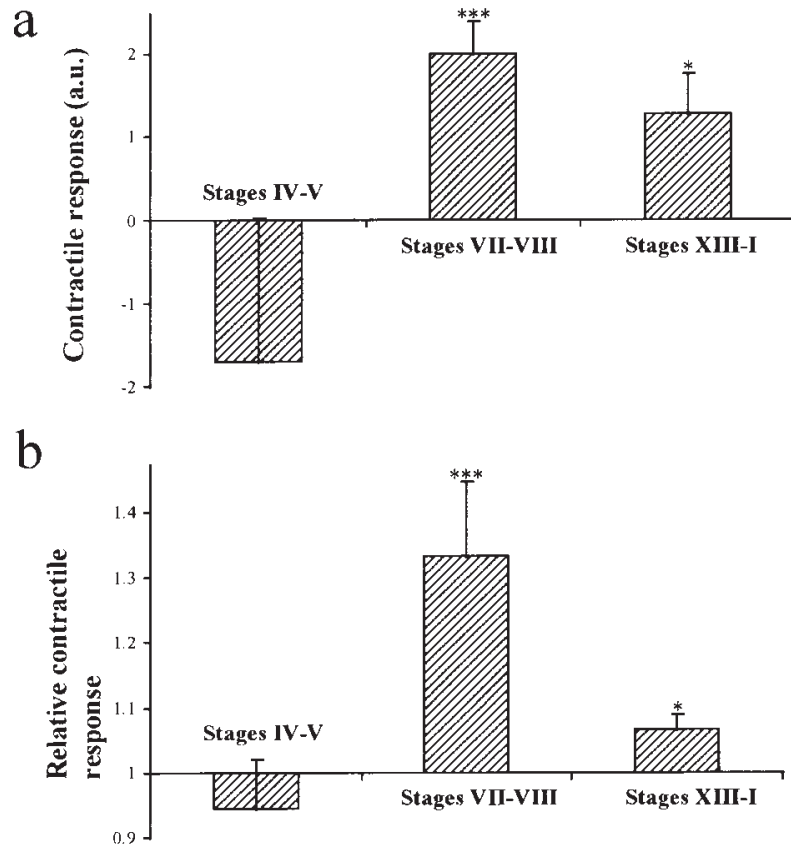

Figure 6 The effects of OT (2 nM) on seminiferous tubule contractility at stages IV-V $(n=6)$, VII-VIII $(n=15)$ and XIII-I $(n=6)$ of the spermatogenic cycle. Data were analysed by linear interpolation. Responses are represented as (a) differences in contractility and (b) relative contractility. Data are expressed as means \pm S.E.M. ${ }^{*} P<0 \cdot 05,{ }^{* * *} P<0 \cdot 001$ vs linearly interpolated control.

\section{Discussion}

We have used a sensitive method to measure seminiferous tubule contractility in vitro, and have demonstrated for the first time that basal contractility varies during the spermatogenic cycle of the rat. Interestingly, basal contractility was lower in vitro at stages VII-VIII, i.e. at the time sperm are shed from the seminiferous epithelium. These findings support earlier work, where the presence or absence of any contractile activity of individual tubules was studied under real time (Suvanto \& Kormano 1970). These workers suggested that a higher proportion (although not significant) of tubules at stage $\mathrm{V}$ of the spermatogenic cycle
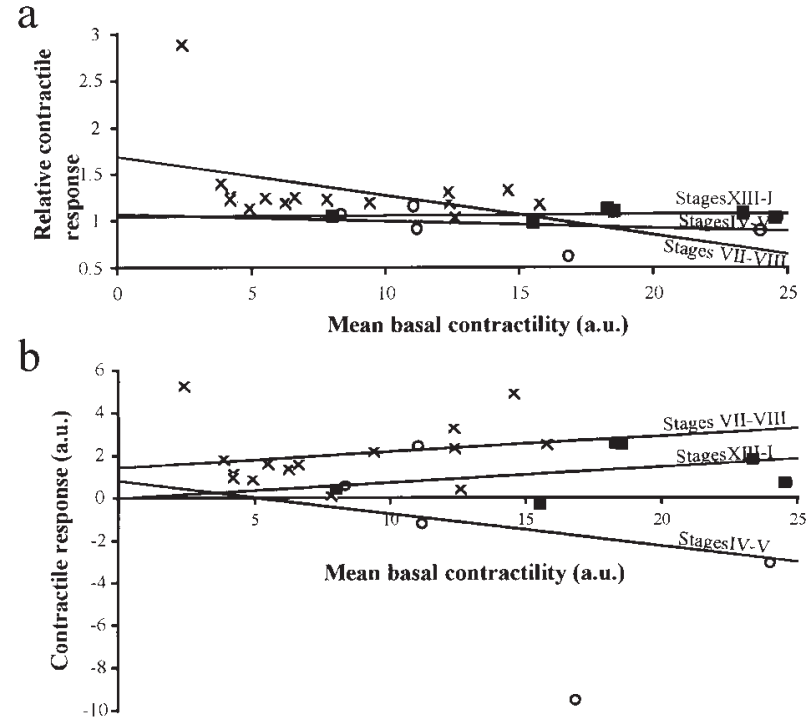

Figure 8 Scatter diagrams of mean basal contractility vs (a) relative contractile response and (b) contractile response (a.u.). $\bigcirc$, stages IV-V $(n=9) ; \times$, stages VII-VIII $(n=15)$; $\mathbf{\square}$, stages XIII-I $(n=9)$.

exhibited some contractile activity compared with stages VII-VIII. In our study, the use of time-lapse videomicrography enabled more accurate analysis and resulted in the detection of significant differences in tubule contractility.

The mechanisms for the differences in basal contractility are unclear. Intralumenal pressure does not seem to play a major role in basal contractility, as seminiferous tubules that lost lumenal contents when they were excised did not display a difference in basal contractility compared with tubules which had been excised so that the lumenal fluid remained sealed in the tubule segment. Instead, contractility appeared to be a genuine, inherent characteristic of the stage of tubule removed. However, the effects of external pressure created by muscle tone in the testicular capsule of the testis in vivo on basal contractility of seminiferous tubules in vitro are not known and this may play a significant role.

We have shown that the decrease in basal contractility at stages VII-VIII of the spermatogenic cycle is not simply

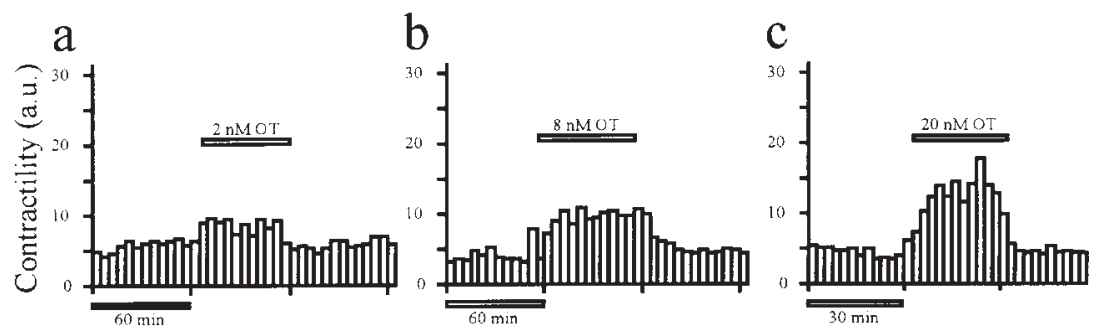

Figure 7 Representative contractility recordings of seminiferous tubules at stages VII-VIII of the spermatogenic cycle showing the effect of (a) $2 \mathrm{nM}(n=15)$, (b) $8 \mathrm{nM}(n=6)$ and (c) 20 $\mathrm{nM}(n=8)$ OT. Each bar represents the mean contractility of the tubule over a 5 min period. 
due to the increase in tubule diameter that occurs at these stages. In contrast, larger tubules if anything possessed greater basal contractility (Fig. 5). It is more likely that basal contractility depends on the increased resistance to bending forces of seminiferous tubules at stages VII-VIII, which may be associated with the maturation and enlargement of developing spermatids. Increased resistance to bending is not simply caused by an increased width of the seminiferous epithelium, as at stages VII-VIII, accompanying the increase in both lumen and tubule diameter, there is a significant decrease in seminiferous epithelium area (Wing \& Christensen 1982, Sharpe 1989). The hypothesis that basal contractility is reduced by the presence of elongate spermatids is supported by the fact that there is higher basal contractility at stage IX of the spermatogenic cycle compared with stage VIII (Fig. 3), as little as $50 \mu \mathrm{m}$ either side from the site of spermiation. Hence, the shedding of spermatozoa may cause a decrease in 'tubule stiffness' and the associated increase in basal contractility. The differences in contractility between stages VIII and IX can be seen further from the site of spermiation, suggesting that the increase in contractility at stage IX is not a remnant of contractility that began in late stage VIII, which may have led to spermiation.

OT and vasopressin are unlikely to be responsible for producing basal contractility, since the peptides are produced by Leydig cells, which were not present in the perifusion chamber. Furthermore, treatment with an OT or vasopressin antagonist had no effect on basal contractility at any stage of the spermatogenic cycle. Since only the seminiferous tubules are included in our preparation, changes in contractile activity are likely to be mediated by factors produced by the seminiferous epithelium, or may be due to the physical properties of the tubules themselves at different stages of spermatogenesis. Many local factors are produced by the testis and it is possible that paracrine factors produced by Sertoli or germ cells may affect myoid cell contractility in a stage-dependent fashion (Skinner 1991).

When considering the relevance of these findings it is interesting to observe that basal contractility is maximal at stages IV-V, a time when spermatids begin their translocation from deep within the seminiferous epithelium towards the lumen surface. The accompanying increase in contractility of the tubule wall may, therefore, help in the movement of spermatids. Conversely, at stages VII-VIII, when spermatids are nearing the lumen in preparation for spermiation, factors which would aid shedding of sperm, such as basal contractility and possibly speed of fluid flow, are lowest (the increased lumenal size at stages VII-VIII would theoretically give rise to a slower 'speed' of fluid flow through this region, although this has not as yet been measured and there may be other factors involved). It is possible that reduced contractility is important in allowing final maturation of the sperm, so that elimination of excess cytoplasm occurs and premature shedding is avoided.
The response of tubules to OT also varied during the spermatogenic cycles. Whilst OT produced a significant increase in contractility at both stages VII-VIII and XIII-I, the response was greater at VII-VIII. The fact that OT produced the highest response in tubules with the lowest basal contractility raises the possibility that OT may induce an equal physiological response in myoid cells at differing stages, but that the response is less clearly seen in tubules which already have a higher basal contractility. However, Fig. 8, which compares the contractile response with basal contractility, suggests that the stage-related effects of OT are due to more than this factor alone. The differential response to OT may reflect alterations in receptor density and this may be further modulated in vivo by the changes in the local production of the peptide by Leydig cells. Although there is no firm evidence that OT is secreted in a stage-dependent manner, the fact that germ cells, and in particular pachytene spermatocytes, can influence OT secretion suggests that this might be the case (Nicholson et al. 1994). The observation that OT has its greatest effect at stages VII-VIII raises the possibility that the peptide may be secreted at a specific point during stage VIII, to provide an increase in contractility to facilitate shedding of the spermatozoa and their subsequent transport along the tubule. Indeed, this hypothesis would agree with evidence indicating that OT appears in the rat testis just before the first sperm are shed, and that the timing of spermiation can be altered by the administration of OT or a specific antagonist in vivo in the pubertal rat (Frayne et al. 1996). However, no noticeable change in the site of spermiation occurred in the tubules whilst studied in vitro, even after treatment with OT.

In conclusion, we have shown that basal contractility varies during the spermatogenic cycle of the rat and we hypothesise that this contractile activity may play a role in the movement of germ cells within the seminiferous epithelium. Furthermore, the demonstration that the response to the testicular peptide OT depends on the stage of spermatogenesis, being greatest at stages VII-VIII, suggests a possible stage-specific role for the peptide in tubular contractility.

\section{Acknowledgements}

The authors would like to thank J A Leendertz for the production of software and hardware essential for tubule contractility analysis. G C H was supported by an MRC studentship.

\section{References}

Buhrley LE \& Ellis LC 1975 Contractility of rat testicular seminiferous tubules in vitro: prostaglandin $\mathrm{F}_{1 \alpha}$ and indomethacin. Prostaglandins $10151-162$. 
Erickson-Lawrence M, Zabludoff SD \& Wright WW 1991 Cyclic protein-2, a secretory product of rat Sertoli cells, is the proenzyme form of cathepsin L. Molecular Endocrinology 5 1789-1798.

Filippini A, Tripiciano A, Palombi F, Teti A, Paniccia R, Stefanini M \& Ziparo E 1993 Rat testicular myoid cells respond to endothelin: characterization of binding and signal transduction pathway. Endocrinology 133 1789-1796.

Frayne J, Townsend D \& Nicholson HD 1996 The effects of oxytocin on spermiation and sperm transport in the pubertal rat. Journal of Reproduction and Fertility 107 299-306.

Gravis CJ 1980 Ultrastructural observations on spermatozoa retained within the seminiferous epithelium after treatment with dibutyryl cyclic AMP. Tissue and Cell 12 309-322.

Harris GC \& Nicholson HD 1998 Characterisation of the biological effects of neurohypophysial peptides on seminiferous tubules. Journal of Endocrinology 156 35-42.

Lacroix M, Parvinen M \& Fritz IB 1981 Localization of testicular plasminogen activator in discrete portions (stages VII and VIII) of the spermatogenic cycle. Biology of Reproduction 25 143-146.

Leblond CP \& Clermont Y 1952 Definition of the stages of the cycle of the seminiferous epithelium in the rat. Annals of the New York Academy of Sciences $\mathbf{5 5}$ 548-573.

Manning M, Cheng LL, Stoev S, Sawyer WH, Tribollet E, Barberis C, Wo NC \& Chan WY 1995 Novel potent and selective antagonists and radioiodinated ligands for oxytocin and vasopressin receptors. In Neurohypophysis: Recent Progress of Vasopressin and Oxytocin Research, Excerpta Medica International Congress Series 1098, pp 21-38. Eds T Saito, K Kurokawa \& S Yoshida. Amsterdam: Elsevier.

Nicholson HD \& Hardy MP 1992 Luteinizing hormone differentially regulates the secretion of testicular oxytocin and testosterone by purified adult rat Leydig cells in vitro. Endocrinology 130 671-677.

Nicholson HD, Worley RTS, Charlton HM \& Pickering BT 1986 $\mathrm{LH}$ and testosterone cause the development of seminiferous tubule contractile activity and the appearance of testicular oxytocin in hypogonadal mice. Journal of Endocrinology 110 159-167.

Nicholson HD, Worley RTS, Guldenaar SEF \& Pickering BT 1987 Ethane-1,2-dimethanesulphonate reduces testicular oxytocin content and seminiferous tubule movements in the rat. Journal of Endocrinology 112 311-316.

Nicholson HD, Greenfield HM \& Frayne J 1994 The effect of germ cell complement on the presence of oxytocin in the interstitial and seminiferous tubule fluid of the rat testis. Journal of Endocrinology 143 471-478.

Niemi M \& Kormano M 1965 Contractility of the seminiferous tubule of the postnatal rat testis and its response to oxytocin. Annales Medicinae Experimentalis et Biologiae Fenniae 43 40-42.

Parvinen M \& Ruokonen A 1982 Endogenous steroids in the rat seminiferous tubules. Comparison of the stages of the epithelial cycle isolated by transillumination-assisted microdissection. Journal of Andrology 3 211-220.
Pickering BT, Birkett SD, Guldenaar SD, Nicholson HD, Worley RTS \& Yavachev L 1989 Oxytocin in the testis: what, where, and why? Annals of the New York Academy of Sciences 564 198-209.

Romrell LJ \& Ross MH 1979 Characterization of Sertoli cell-germ cell junctional specializations in dissociated testicular cells. Anatomical Record 193 23-42.

Roosen-Runge EC 1951 Motions of the seminiferous tubule of rat and dog. Anatomical Record 133 (Suppl) 109.

Schmidt A, Audigier S, Barberis C, Jard S, Manning M, Kolodziejczyk AS \& Sawyer WH 1991 A radioiodinated linear vasopressin antagonist: a ligand with high affinity and specificity for $\mathrm{V}_{1 \mathrm{a}}$ receptors. FEBS Letters 282 77-81.

Sharpe RM 1989 Possible role of elongated spermatids in control of stage-dependent changes in the diameter of the lumen of the rat seminiferous tubule. Journal of Andrology 10 304-310.

Skinner MK 1991 Cell-cell interactions in the testis. Endocrine Reviews $1245-77$.

Suvanto O \& Kormano M 1970 The relationship between in vitro contractions of the rat seminiferous tubules and the cyclic stage of the seminiferous epithelium. Journal of Reproduction 21 227-232.

Tripiciano A, Palombi F, Ballarini F \& Filippini A 1996 Endothelin receptors in rat testis: myoid cells as a contractile target for endothelin. International Journal of Andrology 19 (Suppl) 28.

Vihko KK, Suominen JJO \& Parvinen M 1984 Cellular regulation of plasminogen activator secretion during spermatogenesis. Biology of Reproduction 31 383-389.

Voglmayr JK 1975 Output of spermatozoa and fluid by the testis of the ram and its response to oxytocin. Journal of Reproduction and Fertility 43 119-122.

Wing TY \& Christensen AK 1982 Morphometric studies on rat seminiferous tubules. American Journal of Anatomy 165 13-25.

Worley RTS \& Leendertz JA 1988 A videomicrographic low-frequency movement analyser (VLMA) and perifusion chamber for recording and analysis of the physical behaviour of seminiferous tubules and other contractile tissues in vitro. Journal of Microscopy 151 61-69.

Worley RTS, Nicholson HD \& Pickering BT 1984 Testicular oxytocin: an initiator of seminiferous tubule movement? In Recent Progress in Cellular Endocrinology of the Testis. Colloques de l'INSERM, vol 123, pp 205-212. Eds JJM Saez, MG Forest, A Dazord \& J Bertrand. Paris: INSERM.

Worley RTS, Appleton MAC, Lyburn ID, Challis JR \& Pickering BT 1988 Concentration-dependent stimulation of seminiferous tubule contractility by oxytocin and its modification by peptide analogues. Proceedings of 10th North American Testis Workshop; Regulation of Testicular Function. Serono, USA; poster 29.

Received 4 June 1997

Revised manuscript received 5 September 1997 Accepted 11 November 1997 